\title{
La (in)traducibilidad de un texto literario: nullum est iam dictum quod non dictum sit prius
}

\author{
Juan de Dios Torralbo Caballero \\ Universidad de Córdoba \\ 122tocaj@uco.es
}

Recibido: 14 de enero de 2010

Aceptado: 10 de octubre de 2010

\section{RESUMEN}

Este artículo investiga un concepto emergente de traducción literaria que trata de integrar los elementos discursivos y culturales. Tras prestar atención a la creatividad singular que el traductor ha de aplicar en su tarea, el trabajo revisa el concepto de unidad de traducción considerando algunos enfoques basados no sólo en la palabra, la oración o el texto, sino también en el discurso y la cultura. Siguiendo algunas definiciones comunes del texto literario, se especifican y se analizan diversas dificultades de la traducción literaria para inferir la posibilidad y los retos inherentes a esta nueva visión de la traducción.

Palabras clave: estudios de Traducción, traducción literaria, ideología, cultura.

The (Im)possibility of Translation of a Literary Text: nullum est iam dictum quod non dictum sit prius

\begin{abstract}
This paper discusses an emerging concept of literary translation that aims to integrate discursive and cultural elements. After paying attention to the special creativity the translator needs to apply to his or her task, it revises the concept of translation units taking into account some approaches based not only on the word, the sentence and the text, but also on discourse and culture. Following some standard definitions of the literary text, several difficulties of literary translation are specified and analyzed in order to infer the possibility and the challenges involved in this new vision of translation.
\end{abstract}

Keywords: Translation Studies, Literary Translation, Ideology, Culture. 
Sumario: 1. Introducción: la riqueza de la teoría y los tipos de traducción. 2. Hacia una delimitación de la sustancia a traducir. 3. Caracterización del texto literario. 4. Algunos retos de la traducción literaria. 5. Sobre la (im)posibilidad de traducción del texto literario. 6. Conclusiones.

\section{Introducción: La riqueza de la teoría y los tipos de traducción}

Subtitulamos el artículo con la "primera lección" que Santoyo Mediavilla expresa en su contribución extraordinaria a la obra colectiva La traducción: balance del pasado y retos del futuro, publicada en 2008. Se trata de una cita que escribiera Terencio alrededor del año 161 antes de nuestra era, en el prefacio a Eunuchus. En castellano equivale a "nada queda por decir que no se haya dicho antes". Procedamos, por tanto, con la humildad y cautela que nos aconseja el catedrático leonés. Porque no pretendemos añadir más teoría a la literatura que hay, sino abordar parte de ella. Desde hace más de cuatro décadas, desde que los Estudios de Traducción se implantaron en España, la riqueza de enfoques y abordajes ha vivido una multiplicación elefantiásica que, lejos de abrumarnos o hipertrofiarnos, motivan y animan nuestro quehacer.

En este trabajo se aborda, al principio, el asunto de la unidad de traducción para así mostrar la evolución desde la palabra hasta el giro cultural e historicista que está orientando las teorías del siglo XXI. Seguidamente se enumeran algunos rasgos caracterológicos del texto literario para plantear después sendas dificultades o retos a los que el traductor ha de dar respuesta. En el apartado final se esgrimen motivos sobre la (im)posibilidad de traducción de la obra de arte verbal.

Para delimitar el área de estudio, se hace necesario mostrar a priori la distinción jakobsoniana entre traducción intersemiótica, traducción interlingüística y traducción intralingüística. Roman Jakobson (1975: 69) publica en 1959 "On linguistic aspects of Translation" y expresa que un signo verbal puede ser interpretado de tres modos diferentes: "rewording, translation proper, transmutation". Si se traducen signos verbales mediante otros signos de la misma lengua tiene lugar la traducción intralingüística o reformulación ("rewording"). Si se interpretan signos verbales mediante otra lengua se realiza la traducción interlingüística o traducción propiamente dicha ("translation proper"). En tercer lugar, si se traducen signos verbales mediante signos de un sistema no verbal, ocurre la traducción intersemiótica o transmutación ("transmutation"). Jakobson amplía la noción de traducción a todo proceso interpretativo de signos de los cuales la traducción de lenguas es una ilustración ejemplificadora más. Ello no obstante, el estudioso del círculo de Praga señala que la traducción interlingüística es la verdadera traducción. Otros autores siguen esta aseveración (Ljudskanov 1969, Arcaini 1986). Steiner (1975), por su parte, esboza la traducción interlingüística como un caso particular de comunicación y amplía el concepto a las otras dos aludidas por Jakobson. La vastedad del asunto surge cuando se buscan los límites de la traducción y se añaden bajo este marbete otros conceptos tales como los resúmenes, las adaptaciones de obras, las noticias, el trasvase, la transposición o la re-escritura (Hurtado Albir 2001: 27). 
Considerando los beneficios del rico bagaje terminológico de la disciplina (Vidal Claramonte, 2009: 56) y su fecundidad teórico-crítica, reservamos el término traducción -en la línea propuesta por Jakobson y Steiner- para el trasvase entre lenguas diferentes en la transformación de textos, esto es, para el trasvase entre sistemas lingüísticos diferentes. Encaminemos ahora los pasos hacia la unidad de traducción para nombrar algunos enfoques teóricos que van desde la palabra hasta el nivel discursivo.

\section{Hacia una delimitación de la sustancia a traducir}

El primer enfoque que planteamos es el lexicográfico cuya unidad de traducción es la palabra. Los soportes teóricos que posibilitan su eclosión hunden sus raíces en cauces filosóficos y lingüísticos, concretamente en la filosofía analítica del círculo de Viena y en la vertiente lingüístico-estructuralista. Los antecedentes y fundamentos teóricos se encuentran en el estructuralismo, el que a su vez radica en la antigua Grecia. Este enfoque coincide en la inmovilidad del sentido, en el equivalente ideal y único en el "genio" de cada una de las lenguas. Jakobson (1959) y Mounin, como iniciadores de la tradición lingüística moderna, centran sus investigaciones en la unidad léxica. Las aproximaciones estrictamente lingüísticas también hay que rastrearlas en los orígenes de la sistematización teórica de la teoría de la traducción. Dos son los esfuerzos que se han convertido en hitos que jalonan el camino de la traductología. Uno de 1958, la obra de los canadienses Vinay y Darbelnet, titulada Stylistique comparée du français et de l'anglais; otro, de 1965, el tratado del británico John Cunnison Catford, titulado A Linguistic Theory of Translation.

Estas obras consideran la equivalencia entre un texto y otro como ideal y única. El texto es una estructura cerrada, cuyo lenguaje no cambia, donde el lector no participa en la emergencia de significado y donde el espíritu de la época no cuenta. Para cuestionar esta hipótesis estructuralista y lexicográfica, aludimos a la parábola de Borges en "Pierre Menard, autor del Quijote", en la que no se halla una traducción. Pierre Menard desea escribir El Quijote palabra por palabra. Como resultado final tenemos un caprichoso juego que termina en las mismas palabras, pero con diferentes significados. Este modelo no da respuesta a la complejidad del acto intercomunicativo entre culturas, ya que el enfoque lexicográfico aboga por la sustitución de significantes entre dos lenguas sin la consiguiente modificación de los significados, es decir, presupone la inmovilidad del sentido. ¿Qué es de las metáforas, de las presuposiciones, de las connotaciones y de los matices?

El segundo enfoque es el oracional que tiene como soporte lingüístico a la lingüística oracional con los postulados de Chomsky. Para esta aproximación la unidad de análisis se centra en la oración. Eugene A. Nida, vinculado al "Summer Institute of Linguistics" (S.I.L.), publica junto con Ch. R. Taber, en 1969, un manual cuya consecución final es poder traducir la Biblia a cualquier lengua. The Theory and Practice of Translation supone una clara avanzadilla hacia las vertientes futuras, pues incorpora muy sagazmente los postulados de la pragmática. Exploran el asunto de la equivalencia así como el análisis gramatical y recalcan las proposiciones, las 
estructuras, la función estructural, la retro-transformación y las transformaciones gramaticales. También acuden al sentido referencial y al sentido connotativo por lo que incorporan abiertamente la semántica. Finalmente, se detienen en la transferencia, a lo que dedican más de treinta páginas (todo el capítulo sexto), clasificándola a través de una díada, según resulten modificaciones semánticas o modificaciones estructurales. A pesar de los beneficios para la didáctica, esta aproximación obtuvo manifestaciones críticas en las publicaciones de Dell Hymes (1972), Atchinson (1976) o De Beaugrande (1978).

El tercer enfoque es el textual cuyo soporte epistemológico se instala en la lingüística del texto. Desde mediados de los años sesenta comienza a superarse el análisis oracional y se va incorporando a la lingüística la noción de texto como unidad máxima. El soporte filosófico podría rastrearse en la eclosión de la hermenéutica. La lingüística textual se difunde desde las universidades alemanas, especialmente la de Constanza y, de forma casi coetánea a su nacimiento, presenta un avance fugaz a manos del mismo Chomsky, Kristeva, Petöfi y Van Dijk. La nómina investigadora la componen, entre otros, J. C. Catford (1965), D. Gouadec (1974), E, Coseriu (1977), W. Wilss (1977), K. Hartman (1980), A. Neubert (1985) y G. Garnier (1985). Entre quienes esgrimen el texto como unidad de traducción citemos a Daniel Gouadec quien en 1974 señala (Gouadec, 1974: 20):

\begin{abstract}
Nos unités de traduction seront des unités syntaxiques demandant une connaissance complète de la grammaire anglaise. L'unité de traduction est unité de situation: c'est la plus petite partie de l'énoncé qui suffit à évoquer un élément complet de la situation décrite. Il s'agit du groupe verbal. Le groupe verbal se trouve défini comme un verbe (conjugé) accompagné de tous les mots qui modifient son sens (le groupe verbal correspond en mainte circonstance à une phrase).
\end{abstract}

Los epígonos de esta tendencia encarnan sendas bifurcaciones teóricas que, a modo ilustrativo, son el enfoque hermenéutico que se inicia en la escuela de París centrado en la hermenéutica bíblica, el enfoque funcionalista de Reiss K. y H. J. Vermeer, Nord $(1991,1997)$ y su teoría del 'skopos'; el enfoque comunicativo de Hatin y Mason, profesores de traducción que consideran la traducción como discurso con todas sus variables e insertan en su tratado las variantes de registro y género, que consideran la idea firthiana y hallidayana del texto y trasvasan la dicotomía entre niveles léxico y frástico.

El cuarto enfoque que registramos es el discursivo el cual arranca de sendas tendencias filosófico-analíticas y lingüísticas. El soporte analizable y abstraíble para este enfoque se centra en la comunicación, que se adscribe a la rama conocida como análisis del discurso. Para este enfoque la unidad de traducción es el discurso, consolidada sobre las bases de la nueva lingüística, a la que ahora nos referimos. Enrique Bernárdez (1995: 92-93) agrupa algunas características de la nueva lingüística, al explicar su visión del lenguaje, bajo nueve parámetros. Para Bernárdez el lenguaje parte del uso, resulta de las capacidades cognitivas generales, es dinámico y, como tal, su análisis será procesual, la naturaleza de los fenómenos lingüísticos es estocástica y por tanto la predictibilidad es meramente probabilística, es asimismo con- 
tinua y no discreta, esto es, contiene un componente gradual, las estructuras, que tradicionalmente eran predecibles, dependen del uso real, es complejo y como tal debe ser entendido y estudiado, no es posible abordar su complejidad con los medios formales tradicionales, $y$, en fin, el acercamiento al mismo en toda su complejidad parece adecuado desde las ciencias agrupadas bajo el nombre de caología, ya que con ellas es posible explorar los rasgos naturales y sociales.

Otro de los puntos de referencia en los estudios de traducción contemporáneos es la obra de los citados profesores Basin Hatim e Ian Mason en 1990. Discourse and the Translator es otra guía de obligada consulta en el enfoque discursivo. El libro, tras recorrer algunos debates perennes a la disciplina (literal/libre, equivalencia formal/dinámica -relacionable con la traducción semántica y comunicativa que propusiera Newmark 1981: 39ss.), establece el contexto de traducción centrado en el análisis del registro, considerando los contextos de situación y cultura que propusiera el antropólogo Malinowski, así como los conceptos de significado y variación lingüística de Firth. Una de las premisas del tratado es la consideración del lenguaje como discurso, lo que incorpora la dimensión pragmática, los actos de habla y el principio de cooperación de Grice. Otra de las premisas del mismo es el espacio dedicado a la intertextualidad e intención así como al punto de mira del traductor.

El traductor es el que, a través de una elección motivada, negocia el significado entre el productor y el nuevo receptor. Bajo esta perspectiva el traductor tiene en cuenta el tipo de discurso y la reacción del lector, dos condicionantes que ya consideró Nida en 1964, para así tratar de descubrir el significado adecuado, como señala Steiner y retomarán radicalmente los deconstructivistas. El acto de lectura ${ }^{1}$ es en sí mismo una traducción, esto es, una interpretación, lo cual entronca con el potencial de significado que M. A. K. Halliday define en 1978.

El traductor, según la aproximación discursiva, debe concebir la terminología como vehículo de cultura (transacción comunicativa). A la vez debe no obviar la acción pragmática como, por ejemplo, las estrategias de cortesía destinadas a asegurar la interacción cooperativa o los cambios de tono. El artífice de la traducción también ha de considerar que la intertextualidad² (Martínez 2001: 31, 45-73) que está en la naturaleza comunicativa de los textos y genera una red de mutua dependencia entre los mismos. El estudio de Hatim y Mason postula la tarea del traductor como visión concreta del lenguaje en el seno de la vida social.

Entre los impulsores de volúmenes traductológicos cuya idea subyacente es el texto en su contexto, podemos citar tres a modo de ejemplo: Ortega Arjonilla (2003, 2007) con su enfoque comunicativo-hermenéutico, Z. Lovovskaya (1997) con su enfoque comunicativo-funcional y Vidal Claramonte $(1995,2003,2008)$ imbuida en su visión posmoderna sobre la manipulación y bajo el concepto de representación.

\footnotetext{
1 Una documentada y pedagógica aproximación a la lectura literaria es la que realiza $\mathrm{M}^{\mathrm{a}}$ Ángeles Hermosilla Álvarez (1997: 155-175).

2 Además de la obra señera de José Enrique Martínez Fernández, citamos un estudio panorámico sobre el concepto de intertextualidad realizado por Rosa E. Montes Doncel y Ma José Rebollo Ávalos, publicado en Alfinge 18 (2006) 175-180. El trabajo es "La intertextualidad (1967-2007). El largo periplo de un término teórico".
} 
Cedamos la palabra a la concreción y creación literarias, para reflejar otras notas definitorias sobre su singularidad que nos permitan, más adelante, plantear algunos retos característicos de la traducción literaria.

\section{Caracterización del texto literario}

Terry Eagleton define la literatura y el lenguaje literario basándose en la distinción realidad-ficción y entresaca (Eagleton 1983: 2) una frase jakobsoniana a propósito de la definición: "organized violence committed on ordinary speech". El crítico marxista acude a los postulados de la asociación lingüística de Moscú para dar cuenta de la transformación e intensificación que la literatura supone a la lengua ordinaria y cómo se desvía de manera sistemática del lenguaje diario mediante el uso autorreferencial, esto es, cuando el lenguaje habla sobre sí mismo.

René Wellek toma un poema como caso paradigmático de literatura y lo define como una secuencia de sonidos (Wellek 1942: 212) en base a una experiencia mental que ocasiona placer al lector, aunque añade que el texto también ha generado placer al compositor en el momento de la elaboración. Define el poema como "an artifact, an object of the same nature as a piece of sculpture or a painting", por lo que equipara la obra literaria con cualquier otra obra de arte. La obra de arte verbal puede ser conceptualizada también en base a la experiencia social que supone, en tanto que experiencia colectiva, estar centrada en el receptor o en la audiencia. Con todo, explica Wellek que:

The work of art, then, appears as an object of knowledge sui generis which has a special ontological status. It is neither real (like a statue) nor mental (like the experience of light or pain) not ideal (like a triangle). It is a system of norms of ideal concepts which are intersubjective. They must be assumed to exist in collective ideology, changing with it, accessible only through individual mental experiences, based on the sound-structure of its sentences.

T. S. Eliot, en "Tradition and the individual talent" (1919) acude a la tendencia histórica, al pasado en el presente para ilustrar cómo una obra literaria bebe necesariamente de otras para crear su propia razón de ser:

Tradition is a matter of much wider significance. It cannot be inherited, and if you want it you must obtain it by great labour. It involves, in the first place, the historical sense, which we may call nearly indispensable to anyone who would continue to be a poet beyond his twenty-fifth year; and the historical sense involves a perception, not only of the pastness of the past, but of its presence [...]. The existing order is complete before new work arrives; for order to persist after the supervention of novelty, the whole existing order must be, if ever so slightly, altered; and so the relations, proportions, values of each work of art toward the whole are readjusted.

Edmund Burke, en su Lexicon Rhetoricae (Burke 1931: 234-259) intenta desentrañar los entresijos formales que entretejen la obra de arte literaria. Así, trata de 
definir los principios subyacentes en literatura. Cita más de veinte principios y los explica como vertebradores de la naturaleza formal. Pensamos que, en general, aglutinan sistemáticamente los ingredientes diferenciadores y caracterológicos del hecho literario. Citamos a continuación algunos de ellos: forma, progresión silogística, progresión cualitativa, forma repetitiva, forma convencional, formas menores, interrelación de formas, conflicto de formas, ritmo y rima, forma significativa, llamada de formas, prioridad de formas, individualización de formas, forma e información, forma e ideología, el símbolo y el símbolo como principio generador.

Otras aproximaciones al lenguaje literario aluden (Auden \& Garret 1935: v) al "estilo memorable" frente al estilo trivial y conjeturan el vuelo poético como síntoma neurótico, como un balance compensatorio mediante la fantasía. Así se expresan W. Auden y J. Garret en 1935. La prospección de estos autores se centra en el lenguaje creativo que el hacedor de poesía pergeña.

I. A. Richards, abanderado de la nueva crítica anglosajona ("New Criticism") desenreda cada uno de los hilos de un poema a través de su análisis. Para Richards el resultado de lectura debe concluir con seis acontecimientos (Richards 1925: 117133): sensación visual, imágenes asociadas con dichas sensaciones, imágenes libres, referencias o pensamientos variados, emociones y actitudes afectivo-volitivas. Las imágenes de la obra pueden estar interconectadas o libres y en un caso u otro deben ayudar a desentrañar la urdimbre tanto de emociones (emocional) como de actitudes que haya gestado y genere el poema. Para ello el lector se sirve de "impulsos y referencias".

Para Stephen Spender, (1946) un poema es una secuencia de imágenes sustentadas en la memoria (Spender 1949: 24), alcanzadas a partir de la inspiración, a través de la "concentración inmediata o completa". La plasmación de tales imágenes mediante la música resulta en un "intense physical excitement", una eclosión de éxtasis.

Wallace Stevens (1960: 140), por su parte, centra el hecho literario en la imaginación. Partiendo de este aserto ("we live in the mind"), que lo injerta con los postulados de Pascal (133) o Fichte (136), aduce que todo poema pertenece a otro poema y que si bien procede de la mente es una "revelación", es "esencial" más que "artificial". Su propia definición de poesía dice así (Stevens 2002: 97): "poetry has to be something more than a conception of the mind. It has to be a relation of nature. Conceptions are artificial. Perceptions are essential"; su concepción de poema es que (61) "every poem is a poem within a poem: the poem of the idea within the poem of the words". La literatura como brote imaginativo es abordada también por Northrop Frye en Words with Power (1990) en estos términos: "Literature is not only the obvious but the inescapable guide to higher journeys of consciousness". Considerando las reflexiones tanto del norteamericano como del canadiense y estableciendo un tándem Stevens-Frye, planteamos la literatura como un vuelo reversible cuya estación de partida es la mente y cuyo puerto de llegada recorre los entresijos elevados de la conciencia.

El mismo año que Frye publica el citado libro, Martínez García expresa en Sobre el lirismo que el texto es un objeto lingüístico-cultural a la vez que infiere que no es un objeto físico, sino cultual y, por ello, intersubjetivo. Una década más tarde Mar- 
tínez Fernández (2001: 31) colige no sólo que el texto se inserta en un acto de comunicación donde se evidencian vínculos con la cultura, sino también que se implican nociones como "modelos de mundo" y consideraciones sobre las culturas provenientes de los semiólogos soviéticos. La semiótica de la cultura supuso un nuevo amanecer en los estudios del texto. Martínez Fernández (2001: 19), apoyándose tanto en las investigaciones de Lotman (1996: 78) como en los estudios de Pozuelo (1988: 72), reconoce la insuficiencia de la expresión lingüística para que algo pueda ser considerado como texto.

\section{Algunos retos de la traducción literaria}

El infinitivo "traducir" proviene del latino "trans-ducere" que significa llevar de un lado a otro y es, precisamente, en ese desplazamiento donde se conserva o se pierde parte del tejido que hay en el texto de partida. En este camino radia la miseria y el esplendor de la traducción. En primer lugar, se razonan algunas dificultades que son inherentes al propio traductor para cartografiar luego otros retos que son intrínsecos al mismo texto o tejido lingüístico.

Comencemos por la comprensión que, identificada por García Yebra (1983: 127130), es uno de los problemas que atañen a la relación entre el traductor y el texto original. En el segundo epígrafe hemos mentado la lectura literaria. Pues bien, la comprensión se integra en el acto de leer, hace uso de la hermenéutica ${ }^{3} \mathrm{y}$, en este contexto, los senderos se bifurcan de nuevo porque el traductor debe interpretar y para ello necesariamente ha de inclinarse por unas opciones determinadas en detrimento de otras. De modo apriorístico, el re-escritor tiene que optar por reconstruir la misma intención del primer autor o por adaptar y acercar el contenido al terreno del receptor. Otra de las tareas del traductor es la descodificación del sentido denotado y connotado. Coincidimos plenamente con Martínez Fernández (2001: 31) cuando aduce que "la intención de los significados denotados es de orden preferentemente filológico; la de los significados connotados es de orden hermenéutico".

La capacidad expresiva del traductor en su propia lengua o en la lengua a la que desee traspasar el texto es un factor accesorio a contemplar. Es otra de las operaciones previas al proceso "traslaticio" de carácter decisivo. Comprensión y expresión, pues, se complementan y son dos factores exógenos a los que el traductor debe dar respuesta, porque, en consonancia con Rosa Rabadán (1991: 63) la "experiencia cognitiva puede expresarse en cualquier lengua: la cuestión es superar las barreras impuestas por la organización estructural peculiar de cada sistema”. La formación del traductor también deseamos que conste en esta secuencia multifactorial, ya que el bagaje formativo del traductor (terminológico, cultural, etc.) está al servicio de la

${ }^{3}$ La bifurcación entre una "hermenéutica de la reconstrucción" y "de la integración" nos parece harto productiva y didáctica para aplicarla incluso a la traducción literaria, ya que el re-escritor tiene que decidir de forma apriorística si quiere reconstruir la intención del autor o si prefiere acomodar el texto al entorno pragmático de los potenciales lectores (Hermosilla Álvarez 1997). 
factura de su traducción. Leonardo $\mathrm{Bruni}^{4}$, a comienzos del siglo XV, asevera: "Recte auten id (scil. interpretationem) facere nemo potest, qui non multam ac magnam habeat utriusque linguae peritiam".

Señalemos ahora otra serie de retos, en ocasiones más tangibles que los anteriores, cuales son la polisemia, la ambigüedad, los tropos y las desviaciones. A estos añadiremos unas notas sobre el contexto y la cultura.

La polisemia es identificada por García Yebra (1982, I: 98) como uno de los problemas de índole lexicográfica. Se trata, en realidad, de un recurso semántico que se halla en el potencial significativo de la lengua. Es un escollo consustancial al texto que el re-escritor debe sortear. Ullmann afirma que Michel Bréal, en 1921, es el primero en usar el término ('polysémie'). Un solo signo lingüístico simple o complejo puede adquirir varios significados. Pero a pesar de su universalidad y de su inherencia en la estructura fundamental del lenguaje no parece éste un problema axial porque se resuelve relacionando el signo lingüístico con su contexto. Aristóteles ${ }^{5}$ ya advierte este fenómeno:

[...] no se puede discutir aportando las cosas mismas, sino que usamos los nombres como símbolos en vez de las cosas [...]; los nombres y el número de los enunciados $\left(\lambda \operatorname{ó}_{0} \zeta\right)$ son finitos, mientras que las cosas son infinitas en número, por lo cual es necesario que un mismo enunciado y un solo nombre signifiquen varias cosas.

La ambigüedad es otro de los rasgos implícitos al lenguaje que transporta al traductor al campo de la semántica. Las palabras pueden no denotar exactamente un significado referencial unívoco, por el contrario pueden contener varios significados a la vez y no sentar con claridad uno de ellos. La maestría y la fidelidad del re-escritor, no con la obra en cuestión sino con el lenguaje literario en general, estriba en saber dejar esta ambigüedad hallada en el texto original en su producto post-procesado. La ambigüedad, pues, lejos de convertirse en un problema resoluble es uno de los ingredientes creativos y valiosos del lenguaje artístico que no se debe tratar de anular o de minimizar, pues la ambigüedad es -en términos borgianos- una riqueza (Borges 1971, 2001a: 52) según muestra en el referido relato "Pierre Menard: autor del Quijote". William Empson (1995) por su parte, también elabora un fecundo tratado al respecto en Seven Types of Ambiguity.

Los tropos constituyen un campo de trabajo complejo para el traductor y para el traductólogo. Están relacionados con la pretendida economía lingüística y atañen a la inteligibilidad comunicativa del lenguaje. El empleo de los tropos (ôñóðió) supone una "desviación" o "vuelta" en el plano del contenido (es una manera peculiar de actuar o presentarse). El tropo supone la utilización de una palabra en sentido distinto al que propiamente le corresponde. Los tropos son figuras retóricas o literarias

\footnotetext{
${ }^{4}$ La cita procede de Rolf Kloepfer, quien la toma de Humanistische Prosatexte aus Mittelalter und Renaissance, Tübingen 1957, ed. de J. Stackelberg, p. 67. La traducción: No puede traducir bien quien no sea muy experto en ambas lenguas.

${ }^{5}$ Se cita a través de García Yebra (1982, I: 99) y procede de De sopistici. Elenchi.
} 
tales como la metáfora, la metonimia, la sinécdoque, el pleonasmo, la tautología, la perífrasis, el oxímoron, la paradoja, la antítesis, el símil, el símbolo, la alegoría, la ironía, la hipérbole o la lítotes.

Otras "desviaciones", que Leech (1969: 4) denomina "schemes" en el plano de la expresión son las repeticiones tales como la anáfora, la epífora, la complexión (que es la presencia de ambas), la reedición, la germinación, la antístrofe, la diácope, la diseminación, la concatenación, el polisíndeton, la derivación o el polípote. Estas figuras generan un paralelismo inusitado. La musicalidad y los efectos fónicos también ocurren cuando se presenta, por ejemplo, la onomatopeya, el ritmo, la rima, el metro, las pausas o el encabalgamiento.

El contexto como constructo mental que el receptor elabora es otro parámetro a tener en cuenta en esta clasificación. Sperber y Wilson (1986: 15) definen el contexto como "psychological construct, a subset of the hearer's assumptions about the world" y "the set of premises used in interpreting it". Cinco años después, ErnestAugust Gutt alude al principio de relevancia, en virtud del cual (1991: 33) "an utterance must achieve adequate contextual effect and put the hearer to no unjustifiable effort in achieving them". Precisamente aquí estriba la maestría traductiva, pues, el traductor trata de mantener la relevancia óptima en el vertido definitivo, ya que (Sperber \& Wilson 1986: 185) "every act of ostensive communication communicates the presumption of its own optimal relevance". De este contexto al contexto situacional (planteado por el antropólogo W. Malinowski, en el seno de la etnolingüística conductista) es fácil apreciar cómo el primero -que identificamos como más arduo en la labor traductora- es más abstracto, pues pertenece a la etnolingüística cognitiva que propusiera Lévi-Strauss, y cómo el segundo es tangible y determinado. De hecho, la expectativa de relevancia óptima se ubica en el plano cognitivo, pues las circunstancias situacionales, los factores culturales que tan axiales son para el traslado del texto conforman "part of their assumptions about the world or cognitive environment". El criterio del re-escritor para seleccionar los aspectos relevantes y trasvasarlos al lector meta tiene que ver, precisamente, con el dinamismo del contexto cultural, que es de motivación cognitiva. Esta transposición, debido a la naturaleza contextual del receptor, permite la interpretación, que nunca es idéntica a la de los lectores originales, del texto traducido. Gutt (1991: 27) establece que "human beings have a natural interest in improving their understanding of the world around them; this understanding consisting of the assumptions about the world which they have stored in memory" y añade que "hence they expect that the effort sent in comprehension will in some way modify the contextual assumptions they brought the communication act".

La tarea del re-escritor consiste, pues, en conciliar la diferencia entre las dos culturas, de acercarlas equiparándolas o de alejarlas a base de diferenciarlas, dependiendo del substrato receptor que los lectores nuevos posean y según desee orientar su traducción. Consiste en traducir al otro, en hacerlo comprensible. En hacer comprensible la lengua en otra lengua, la identidad en otra identidad y la cultura en otra cultura. Ésta es una de las grandezas del traductor y del traductólogo; también están las dificultades porque según S. Pit Corder (1973: 73) "[...] the difficulty of learning a foreign language is related to the degree of difference between two cultures". 


\section{Sobre la (im)posibilidad de traducción del texto literario}

Con estos retos, a los que el nuevo creador debe responder, nos hacemos una pregunta que se desprende del título del artículo y, además, planteamos otro interrogante derivado del primero. ¿Es posible la traducción literaria? ¿Merece la pena disponer de la obra de arte literaria en una versión traducida? Nuestra respuesta a la primera cuestión es claramente afirmativa. Otro asunto es objetivar si la traducción destiñe, desdora, cambia o mejora sustancialmente el texto fuente; o incluso si se apega o se despega del original, si muestra más convergencia con la forma o con el contenido.

El término, llegados a este punto de la disertación, es lo de menos. Pensamos que da igual decir "traduire, tradurre, transferre, übersetzen; traduire; versio, convertere, interpretare" o "volgarizzare". Otras expresiones empleadas son "romanzar" o "vulgarizar". "Vulgo", en latín, significa: divulgar, publicar o propagar y "vulgus" quiere decir pueblo o público. Lo que importa es que, en esa cultura o sociedad donde se aclimate el texto, muchos lectores puedan disfrutar de la obra literaria. Aplicando los términos del estructuralista praguense Mukarovsky, se trata de que la obra de arte verbal se convierta en un objeto estético y no se quede en mero artefacto ${ }^{6}$. Lo que cuenta, estimamos que para nuestro bien, es que si la obra no fuese "trans-ducida" a otras latitudes y a otro idioma, la leerían menos personas. Por esto, queremos la "vulgarización", es decir, que la obra llegue a muchos receptores. Entendiendo, incluso, que cada texto literario porta una sustancia intraducible ${ }^{7}$ (sea material como algunos significantes o menos tangible como parte del contenido cultural), estimamos que más vale disponer de la obra fuente en traducción a tenerla en un lenguaje extraño que gran parte de los potenciales lectores no entenderían.

Pongamos algunos ejemplos, principalmente del ámbito anglosajón, que constatan que el menester de traducir literatura viene de antiguo. A la traducción se dedicaron Lady Margaret Beaufort, Aphra Behn y Elizabeth Cary. Dryden se dedicó a la traducción cuando le falló el apoyo de la corte y, cuando tuvo que cambiar la pluma teatral por la traducción de los clásicos, se cuentan 1.400 libras entre sus ganancias por The Works of Virgil. La traducción aportó también ingresos económicos a Erasmo o Samuel Johnson. Alexander Pope ganó 4.500 libras por traducir la Odisea. La traducción es una forma literaria que participó en los orígenes del libro impreso y propició un mercado en torno al oficio. La traducción albergó patronos. Alfonso X, "El Sabio", o el Cardenal Cisneros encargaron la traslación de textos de una lengua a otra. También hay patronas como Gerónima Palova de Almogáver que encargó la traducción de Cortegiano de Castiglione. La traducción propició empresas e imprentas, empresarios e impresores, como W. Caxton en Londres, Etinne Dolet en Lyon o Barezzo Barezzi en Venecia.

\footnotetext{
${ }^{6}$ Estos conceptos se encuentran en varias obras del autor. Consideramos muy fructífera la consulta, al menos, de estas dos: On Poetic Language (1976) (traducida por John Burbank y Peter Steiner) y en The Word and Verbal Art: Selected Essays (1977).

${ }^{7}$ Resulta ameno el estudio que ha realizado Alejandro Bekes titulado Lo intraducible: ensayos sobre poesía y traducción, que ha sido merecedor del VI Premio Internacional de Crítica Amado Alonso, publicado en Pre-Textos en 2010.
} 
De traducciones se nutre la biblioteca de Letras Universales de Cátedra, con traducciones se forjan parte de la colecciones de Hiperión, Gredos o Galaxia Gutenberg y gracias a las traducciones literarias está proliferando una pléyade de ediciones y editores que cuidan al máximo su maquetación y su encuadernación como son Siruela, Renacimiento, El Acantilado, Krk Ediciones o Clásicosextopiso. Hoy día, quien traduce literatura (principalmente poesía) no lo hace pro pane lucrando, sino más bien por vocación, satisfacción y realización personal. Quien hoy traduce literatura, en su mayoría, lo hace por el placer de escribir o de recrear su formación aplicando sus dotes creativas.

Dar una respuesta satisfactoria a las dificultades es parte de la tarea del traductor o re-escritor. Aquí está la razón por la cual traducir literatura es un arte. He aquí el motivo por el que un texto literario no puede traducirse de manera automática. Si aplicamos Babel Fish (una de las tecnologías lingüísticas para la traducción) a un poema, los resultados serán deplorables. Por eso las nuevas tecnologías sin la mente creadora de un traductor no pueden postularse como herramienta o método para conseguir el acabado deseable en la traducción literaria. Amelia Gamoneda (2008: 5266) habla de "placeres de la traducción" y ello desde el quehacer intrínseco del oficio. En concreto (Gamoneda 2008: 57) confirma lo siguiente:

Estoy hablando de los placeres de traducción que tienen raíz vital e incluso libidinal. No creo que la traducción se viva íntimamente como un servicio a la cultura o a los lectores que no manejan una lengua. Creo que, incluso para el filólogo, el gesto de la traducción le implica más como experiencia emotiva, intelectual o poética que como mediación cultural.

Coincidimos con la traductora (Gamoneda 2008: 72) en que el poema intenta recuperar aquel tiempo mágico pre-babélico despertando en la lengua una memoria de lo perdido, activando la potencia del sentido pleno que puede secretamente albergar el signo lingüístico. La misma senda transgresora recorre el traductor y además le añade otra osadía porque pretende activar ese sentido pleno emanado del contacto de dos lenguas. El traductor, igual que el poeta, trabaja en la destrucción de la lengua que utiliza, pero lo hace enfrentando una lengua contra la otra, procurando que sean ellas mismas las que se arañen para que brote el sentido. El traductor de poesía es el mago de la torre, el que convence a una lengua para mirarse y reconocerse en otra como en un espejo.

Traducir es reflexionar sobre cómo viaja (“ducere”) el significado; es hablar desde nuestras palabras en otras palabras ("trans") con el fin de liberar todas las posibilidades del signo para pensar lo mismo de otra manera, respetando la diferencia y la dimensión de la otredad, respetando la equivalencia pero sabiendo, al mismo tiempo, que es imposible, que siempre será una acción imperfecta, porque siempre quedará algo fuera, oculto, que explica su naturaleza fragmentaria, la imposibilidad de quedar intactos tras el viaje. Así se expresa Edwin Gentzler (2008: 2) y así lo expresa $\mathrm{M}^{\mathrm{a}}$ Carmen África Vidal Claramonte (2008: 75). La cultura y la historia -como haz y envés de una misma hoja- están integradas aquí. 
Según hemos argüido al comienzo del trabajo, las únicas unidades de traducción de antaño eran la palabra y la oración. Ahora la unidad de traducción comienza a ser la cultura. Nos alerta Vidal Claramonte (2008: 77) que incorporar la cultura supone dar un vuelco, porque traducir es mucho más que hacer un buen uso de un diccionario. A finales del siglo XX, la Teoría de los Polisistemas y la Escuela de la Manipulación concretan que traducir es manipular. Aquí tiene cabida la historia y la cultura. Nos hemos referido al giro cultural de la traducción. Además, la ideología y los componentes políticos están encontrando acomodo en los anaqueles del traductor $\mathrm{y}$, de modo contiguo, se están aplicando en el proceso "traslaticio". En 1990, Eco apunta hacia "un cambio radical en el paradigma de los estudios literarios".

Una nueva oleada conceptual puebla la mesa del investigador del siglo XXI. Infiere la catedrática de Salamanca que la microfísica del poder que señalara Michel Foucault o la ideología del sentido de Lefevere propician nuevas teorías con los estudios postcoloniales (Niranjana, Cheyfitz o Venuti, entre otros) o con los abordajes feministas (Godard, Lotbiniére-Harwood, Simon, Levine). Se ha pasado de la equivalencia a la cuestión ética. Para refrendarlo, registremos como botón de muestra el segundo capítulo de Meschonnic (2007), titulado "Ética del lenguaje, ética del traducir, urgente".

\section{La singularidad del texto traducido}

El texto traducido o re-escrito estimamos que goza de la misma altura ontológica que el texto fuente. En palabras de Venuti (1992: 9): "What makes the foreign text original is not so much that it is considered the coherent expression of authorial meaning, but that it is deemed worthy of translation, that it is destined to live an afterlife in a derivative form like translation". El texto traducido posee su propia naturaleza, original y autorial (con "auctoritas"). En la última década del siglo XX, la Teoría de los Polisistemas, que eclosionó en la Universidad de Tel-Aviv con I. Even-Zohar, muestra cómo la literatura traducida (rechazada por los círculos dominantes de la cultura) puede alterar los estratos del polisistema entre el centro y la periferia ${ }^{8}$. Partiendo del concepto de importación que empleara Lambert, señalan la heterogeneidad hacia la que deviene una cultura o sistema literario cuando aclimata y no limita la entrada de textos foráneos.

El nuevo texto engloba, por una parte, variables lingüísticas, literarias, históricas, antropológicas o psicológicas; por otra, encierra además unas vertientes ideológicas y poéticas. El tejido lingüístico no es inocente, porque contiene trazos que van desde la antropología hasta el terreno de la ideología o la política. La re-escritura, bajo tal perspectiva, es una manipulación. La traducción, por tanto, es causal -y no casual- porque la reformulación del texto porta ineludiblemente la "auctoritas" y la huella de su nuevo autor. El texto fuente, pues, cuenta con más ingredientes que los puramente semánticos o sintácticos. Para Rafael Burton (1994: X):

\footnotetext{
${ }^{8}$ En 2008 publicamos un breve panorama sobre la traductología, donde se incluye un estudio más detallado sobre esta escuela (Torralbo Caballero 2008).
} 
Prose cannot be adequately translated without close attention to its inner structures: for proper prose translation the necessary and desirable freedom of the poetic translator must be curbed for the basic component of prose style, as well as an important aspect of prose significance (meaning), turns out to be syntax.

En un texto de prosa rigen ciertas normas que condicionan la traducción, por ejemplo la sintaxis y las características estilísticas, las cuales no se han de perder en la transferencia literaria. En lo que atañe a la poesía, el traductor encuentra otros condicionamientos emanados de la anarquía que el texto contiene, idea ésta que explica Walter Nash (1971: 92-93) de la manera siguiente:

He may take cavalier liberties with the syntax of the language, though he never pursues liberty to the point of total disorder; he proclaims, through word-play, image, and metaphor, his right to reassess the values of lexicon; he may even triumphantly assert his privileges status with some turn of language that directly challenges one or another of the terms of our unwritten contract.

Roman Jakobson $(1935,1987: 310)$ cuatro décadas antes, ya alude a estos parámetros retóricos cuando asevera que algunas figuras existentes en poesía rompen la relación frecuente entre el significante y el significado:

The essence of poetic figures of speech does not simply lie in their recording of manifold relationships between things, but also in the way they dislocate familiar relationships. The more strained the role of the metaphor in a given poetic structure, the more decisively are traditional categories overthrown.

Dichas peculiaridades deben ser amoldadas o remodeladas en la nueva versión, que ha de considerar, como se ha dicho, la cultura del sistema fuente. El traductor literario es un filtro mediador entre dos culturas, ya que el texto traducido incide en el desarrollo de la cultura meta a pesar de que su tarea sea "ajustarse y amoldarse" (Álvarez Calleja 2000: 17) perfectamente al texto primero. El traductor no anula su individualidad sino que se identifica con el texto distanciándose de él para producir una nueva emergencia en otro sistema cultural. Por lo tanto, traducir implica una obligación y una responsabilidad, que Frederic Wills (1993: 30): postula así:

No wonder translation talk keeps renewing its normative accent, insisting on the importance of establishing both aesthetic and moral value together. The translator has, of course, no more claim than the poet or novelist to a professional concern with value; and in many senses the creator has the more vivid and instructive inwardliness to value.

La obra original crea materia nueva per se, mientras que el texto nuevo recrea la obra original operando a partir de equivalencias (Nida 1991: 26) que los teóricos deducen al comprobar las posibilidades y limitaciones de diferentes tipos de traducciones. El traductor literario Wills (1993: 152) lo anota con estas palabras: 
Translation's job is to place that equivalence -sounds and sense at work in themat a perfect distance from their source - at a judicious, lively, instructive distance. Knowing that distance, finding it with care, the translation will slip into its own center of gravity, will create its own kind of interiority. Viewed without knowledge of its original, that translation may appear independent; but in fact lively dependent will be the underlying source even of that appearance. Here is part of the mystery of translation's restoration of the Word. The greater the translation's dependence, the more scrupulously it will work away both from the sound and the sense of the original.

Teniendo en cuenta lo antedicho, el re-escritor debe optar por un tipo de traducción determinado. Hemos de volver a nombrar el concepto de equivalencia ${ }^{9}$ aunque sea de modo tangencial. La bifurcación ya la postula Cicerón, en De Optimo Genere Oratorum, mediante la dicotomía "ut interpres" o "ut orator", es decir, indica la posibilidad de traducir como un intérprete o como un orador. El patrón de los traductores, San Jerónimo ${ }^{10}$ de Estridón en su Epístola a Mamaquio, también plantea el par conceptual de traducción "ad sensum" o "ad verbum", a saber, traducir mediante el sentido o apegándose más a la palabra exacta. Nida" ${ }^{11}$, para poder comparar el dualismo de modo diacrónico, postula la oposición entre "equivalencia formal" y "equivalencia dinámica" La primera trata de conservar la forma lingüística que existe en el texto fuente y mantiene los rasgos sintácticos, morfológicos incluso fonéticos en la medida de lo posible, mientras que la "equivalencia dinámica" se centra en conseguir el efecto pragmático del texto origen en los receptores de la lengua meta mediante los recursos de la propia lengua de llegada.

En 1964 Arrowsmith y Shattuck reflexionan sobre los géneros de la traducción citando seis clases ${ }^{12}$ :

Identifiable 'genres' come easily to mind: the literal 'trot' (or 'transposition'), as Mr. Carne-Ross calls it; the scholarly-genteel or belletristic translation; the 'free' version; the 'adaptation'; the 're-creation'; the 'imitation' (in Robert Lowell's sense); and so on. Each of the different 'genres' reflects a basic difference in function; each is good or bad according to its mode, and it is as idle to blame, say, a free version for not being literal (and vice versa) as it is to blame chalk for not being cheese.

9 Para un trabajo claro sobre el concepto de equivalencia, consúltese el artículo de Nuria Ponce Márquez titulado "Diferentes aproximaciones al concepto de equivalencia en traducción y su aplicación a la práctica profesional”, en Tonos digital: Revista electrónica de estudios filológicos, N. 15, 2008.

10 Quien tenga interés en aprender con en una prospección detallada sobre el contexto vital y laboral de San Jerónimo, así como en su legado creativo, puede acudir al artículo de Pilar Martino Alba (2008: 453466). La profesora e investigadora recopila las reflexiones de San Jerónimo en torno a la traducción como proceso y producto y las articula en trece apartados que nos resultan de lectura muy amena.

11 Así lo expresa Nida en Towards a Science of Translation with Special Reference to Principles and Procedures involved in Bible Translation. En la cuarta página de su trabajo define su concepción de traducción en estos términos: Translating consists of reproducing in the receptor language the closest natural equivalent or the source language message, first in terms of meaning, secondly in terms of style.

12 Estas inferencias las coligen en William Arrowsmith y R. Shattuck (1964, $2^{\text {a }}$ ed.) (eds.), The Craft and Context of Translation, Garden City, New York, Anchor Books, p 13. 
En esta línea se inscribe la hermenéutica ${ }^{13}$ de Schleiermacher con su díada entre 'dolmetschen' y 'übersetzen', Claudio Guillén (1985: 351) con 'literal' y 'libre' o Lefevere con su dicotomía entre 'text-oriented' y 'reader-oriented'. Más reciente es la clasificación de Lörscher ${ }^{14}$ sobre traducción orientada al signo y traducción orientada al sentido.

\section{Conclusiones}

El cambio de paradigma en los estudios literarios que señalara Umberto Eco se correlaciona con las nuevas aproximaciones que han germinado en la historia y teoría de la traducción. Los enfoques que hemos planteado al principio del artículo son el lexicográfico, de corte estructuralista; el oracional (post-estructuralista), de corte generativo; el textual (post-generativo); el discursivo (post-textual); y, en fin, el comunicativo (o neo-formalista, post-discursivo). Aquí hemos incorporado el giro cultural e historicista que ha hecho avanzar a los estudios de traducción y que incorpora los elementos que conforman las sociedades, las variables interculturales, el contexto o la diversidad interna de la cultura. Estos ingredientes se reflejan en los textos literarios y añaden complejidad a la vez que enriquecen el esfuerzo y el arte de traducirlos.

De aquí se desprende que el terreno teórico de la traductología no puede circunscribirse solamente a la lingüística ni incluso al análisis del discurso. El área de los estudios de traducción debe roturarse con la teoría de la literatura, la poetología, los estudios culturales, hitoriográficos e incluso políticos, pero además ha de abonarse con los postulados de la estilística y de la retórica. Por tanto, el traductor -autor también- se provee de respuestas de calado lingüístico, retórico, poético, cultural, ético y político.

Ciertamente, la obra de arte verbal contiene una sustancia cultural que el traductor no puede ignorar, a la par que ha de dar respuestas satisfactorias a realidades tales como la polisemia, la ambigüedad, los tropos, las desviaciones y tener en cuenta el contexto, tanto de emergencia de la obra fuente como de recepción del nuevo texto.

La "violencia" que ejerce la literatura sobre el lenguaje ordinario, en palabras de T. Eagleton, es uno de los parámetros que dificulta, aunque no impide, la traducción literaria. El hecho de traducir un fragmento literario se convierte en una obra de arte, en un esfuerzo artístico y creativo. El texto literario contiene unas características especiales, tales como el deleite que disfruta la mente del receptor (en términos de Wellek) o el mosaico de fusión e influencia históricas (según Eliot), la forma pecu-

\footnotetext{
13 Henri Meschonnic también recoge estas dualidades en el segundo capítulo de su libro (2007). Existe traducción española realizada por Hugo Savino (2009: 12).

14 La citada referencia la inserta Elena Sánchez Trigo en su colaboración a la obra colectiva coeditada por ella misma (2000), p. 116. W. Lörscher, por su parte, lo publica en 1991, en Translation, Performance, Translation Process and Translation Strategies, Tubinga, Günter Narr, concretamente en p. 276.
} 
liar (aplicando el estudio citado de Burke), el estilo memorable (tal como explican Auden y Garret) o la sensación de imágenes y la imaginación (según Richards, Spender y Stevens).

En la elaboración y reelaboración de estas singularidades, el nuevo escritor pone en juego y recrea su comprensión así como su capacidad expresiva. Con todo, hemos de nombrar, sin llegar a compartir el adagio italiano "traduttore, traditore", que es imposible que el texto quede modelado con el mismo contorno morfológico, sintáctico, semántico, pragmático y cultural que la muestra original. Si el traductor aboga por la forma, ha de desteñir algunos tintes semánticos y viceversa.

Cervantes en el capítulo VI de la primera parte de su obra magna lo explica así: "y lo mesmo harán todos aquellos que los libros de verso quisieren volver en otra lengua: que, por mucho cuidado que pongan y habilidad que muestran, jamás llegarán al punto que ellos tienen en su primer nacimiento". Después, en el capítulo LXII de la segunda parte, Don Quijote explica que traducir de una lengua a otra es como mirar los tapices flamencos por el revés; que aunque se ven las figuras, están llenas de hilos que las oscurecen, y no se ven con la lisura y la tez de la haz. Con estas taras y restas, claro, confiamos y compartimos el esplendor de la traducción literaria.

Volviendo al inicio. La exuberante producción teórica sobre la (in)traducibilidad de un texto literario nos extasía y la consideramos, de hecho, necesaria. Esta copiosa producción denota la actualidad de la disciplina de los Estudios de Traducción en la segunda década del siglo XXI. Corrobora su vigencia y hace tangible parte de la labor que se viene desarrollando en Revistas, Seminarios, Congresos, Simposios, obras colectivas y un sinfín de trabajos individuales que se están realizando en los diversos Departamentos de Traducción y Filologías, no sólo en nuestro país sino a nivel mundial. Para finalizar este trabajo, permítasenos citar tres ejemplos de reuniones científicas periódicas sobre traducción que se celebran en nuestro país. Primero, las Jornadas de Traducción Literaria y Científico-Técnica que prepara, año tras año, el Departamento de Filología Inglesa de la Universidad de Extremadura en la Facultad de Filosofía y Letras (Cáceres). En segundo lugar, los Encuentros Complutenses en torno a la Traducción que organiza, bianualmente, el Instituto Universitario de Lenguas Modernas y Traductores de la Universidad Complutense de Madrid. Finalmente, el Congreso Internacional de Traducción, Texto e Interferencias, con carácter itinerante y de gestión inter universitaria.

\section{Referencias bibliográficas}

Álvarez Calleja, M. A., Traducción y lenguajes literarios: Escritura autobiográfica norteamericana. Madrid: UNED 2000.

Auden, W. H., / Garret J., «Introduction», The Poet's Tongue. London: G. Bell \& Sons Ltd 1935, v-x.

Baker, M., In other words, a coursebook on translation. London: Routledge 1992.

Balbuena Torezano, C. \& A. García Calderón, Traducción y mediación cultural. Granada: Atrio 2007.

Bernárdez, E., Teoría y epistemología del texto. Madrid: Cátedra 1995. 
Blanco García, P. (ed.), El Cid y la Guerra de la independencia: dos hitos en la Historia de la Traducción y la Literatura. Madrid: Instituto Universitario de Lenguas Modernas y Traductores 2010.

Burke, K., «Lexicon Rhetoricae», Counter-Statement. New York: Harcourt 232-249.

Burke, P. y R. Po-Chia Hsia (eds), Cultural Translation in Early Modern Europe. Cambridge: Cambridge University Press 2007.

Corder, S. P., Introducing Applied Linguistics. London: Penguin 1973.

Derrida, J., La verdad en pintura, trad. de M. C. González y D. Scavino. Barcelona: Paidós 2001.

Eagleton, T., «Introduction: What is Literature», Literary Theory. An Introduction. Oxford: Blackwell 1983, 1-16.

Eco, U., Los límites de la interpretación, trad. de Helena Lozano. Barcelona: Lumen 1998.

—, Dire quasi la stessa cosa. Milán: R.C.S. Libri 2003.

Eliot, T.S., The Sacred Wood. Essays on Poetry and Criticism. London: Faber \& Faber (1920) 1997.

Empson, W., Seven Types of Ambiguity. London: Hogarth Press (1930) 1995.

Frye, N., Anatomy of Criticism. London: Penguin Books 1957.

Gamoneda A., «La lengua bífida de la traducción», en: Gómez Montero, J. (ed.), Nuevas pautas de traducción literaria. Madrid: Visor Libros 2008, 37-73.

García Yebra, V., Teoría y práctica de la traducción. Gredos: Madrid (1982) 1997.

Gentzler, E., Translation and Identity in the Americas. New Directions in Translation Theory. London / New York: Routledge 2008.

Gómez Montero, J. (ed.), Nuevas pautas de traducción literaria. Madrid: Visor Libros 2008.

Gouadec, D., Comprendre et traduire. Techniques de la version. Paris: Bordas 1974.

Gutt, E.A., Translation and Relevance: Cognition and Context. Manchester: St. Jerome 1991.

Hermans, T., «Translation Studies and a New Paradigm», en: Hermans, T. (ed.), The Manipulation of Literature. Studies in Literary Translation. London / Sidney: Croom Helm 1985.

Hermosilla Álvarez, A., «La lectura literaria», en: Hernández Guerrero, J. A. (ed.), Manual de Teoría de la Literatura. Sevilla: Algaida 1996, 155-175.

Hurtado Albir, A., Introducción a la traductología. Madrid: Cátedra 2001.

Hymes, D. (ed), Reinventing Anthropology. New York: Pantheon 1972.

Jakobson R., «On Linguistic Aspects of Translation», en: Brower R. A. (ed.), On Translation. Cambridge: Harvard University Press (1959) 1975, 232-239.

Lafarga, F., (ed), La traducción en España (1750-1830). Lengua, literatura, cultura. Lleida: Edicions de la Universitat de Lleida 1999.

Lambert, J. / H. van Gorp, «On Describing Translations», en: Hermans T. (ed.), The Manipulation of Literature. Studies in Literary Translation. London / Sidney: Crom Helm 1985, $42-53$.

Leech, G., A Linguistic Guide to English Poetry. London: Longman 1969.

Lefevere, A., Translation, Rewriting and the Manipulation of Literary Fame. London: Routledge 1992.

Lotman, I. M., La semiosfera I. Semiótica de la cultura y del texto, selección y trad. de D. Navarro. Madrid: Cátedra 1996.

Martínez Fernández, J. E., La intertextualidad literaria. Madrid: Cátedra 2001.

Martino Alba, P., «San Jerónimo: traductor y traductólogo», en: Navarro Domínguez, F. et aliis, Alicante: Aguaclara 2008, 453-466. 
Meschonnic, H., Ética y política del traducir, trad. de Hugo Savino. Argentina: Leviatán 2009.

Moya, V., La selva de la traducción. Teorías traductológicas contemporáneas. Madrid: Cátedra 2004.

Navarro Domínguez, F. et aliis, La traducción: balance del pasado y retos del futuro. Alicante: Aguaclara 2008.

Newmark, P., A Textbook of Translation. London: Prentice Hall 1988.

Nida, E. A., Towards a Science of Translating: with Special Reference to Principles and Procedures involved in Bible Translation. Leiden: Brill 1964.

Ortega Arjonilla, E., «Filosofía de la ciencia y traducción: entre relativismo y normativismo. Aportaciones de la metodología cientírica a la investigación traductológica», en: Ortega Arjonilla, E. (dir.), Panorama actual de la investigación en traducción e interpretación. Granada: Atrio 2003, 59-112.

- (ed.), El giro cultural de la traducción. Berlin: Peter Lang 2007.

Pozuelo Yvancos, J. A., Teoría del lenguaje literario. Madrid: Cátedra 1988.

Rabadán, R., Equivalencia y traducción. Problemática de la equivalencia translémica inglés-español. León: Universidad de León 1991.

Richards, I. A., «The Analysis of a Poem», en: Richards, I. A., Principles of Literary Criticism. New York: Harcourt 1925, 144-133.

Sánchez Trigo, E. (ed.), «Las denominadas unidades de traducción», en: Sánchez Trigo, E. \& Díaz Fouces, O., Traducción y comunicación. Vigo: Servicio de Publicaciones de la Universidad de Vigo 2000, 89-124.

—, Teoría de la traducción: convergencias y divergencias. Vigo: Servicio de Publicaciones de la Universidad de Vigo 2001.

Spender, S., The Making of a Poem. London: Hamish Hamilton 1995, 89-124.

Sperber D., Wilson, D., Relevance, Communication and Cognition. Cambridge: Harvard University Press 1986.

Steiner, G., After Babel. Oxford: Oxford University Press 1975.

Stevens, W., «Imagination as Value», The Necessary Angel. Essays on reality and the imagination. London: Faber \& Faber (1952) 1960, 133-156.

Torralbo Caballero, J. D., Breve panorama de la traductología. Granada: Grupo Editorial Universitario 2008.

Vega, M. A., Textos clásicos de teoría de la traducción. Madrid: Cátedra 1994.

Venuti, L., «Introduction», en: Venuti, L. (ed.), Rethinking Translation: Discourse, Subjectivity, Ideology. London / New York: Routledge 1992.

Vidal Claramonte, M. C. A., Traducción, manipulación, reconstrucción. Salamanca: Colegio de España 1995.

—, «La investigación traductológica a la luz del concepto de representación», en: Ortega Arjonilla, E. (ed.), 2003, 271-278.

—, «Traducir en el siglo XXI: Nuevos retos de la investigación traductológica», en: Gómez Montero, J., 2008, 75-86.

—, "A vueltas con la traducción del siglo XXI", MONti 1(2009), 49-58.

Wellek, R., «The Mode of Existence of a Literary Work of Art», The Theory of Literature. New York: Harcourt 1942, 210-223.

Wellek, R. y A. Warren, Teoría literaria. Madrid: Gredos 1953.

Will, F., Translation theory and practice. Lewiston. New York: The Edwin Mellen Press 1993.

Wills, W., The science of translation: problems and methods. Tübingen: Narr 1982. 